\title{
Do HIV-Infected Incarcerated Sexual Offenders Deserve a Little More Attention?
}

\author{
Danilo Antonio Baltieri*,1,2 and Douglas Pieter Boer ${ }^{1,3}$ \\ ${ }^{1}$ Psychiatry Institute of the Clinical Hospital, The University of São Paulo, Brazil \\ ${ }^{2}$ Ambulatory for the Treatment of Sexual Disorders, ABC Medical School, Santo André, São Paulo, Brazil \\ ${ }^{3}$ School of Psychology, The University of Waikato, Hamilton, New Zealand
}

\begin{abstract}
Sexual offenders are putatively at high risk of contracting and transmitting HIV as a result of their nonconsensual and coercive sexual practices. To identify and manage particular health and psychological needs among infected sexual offenders should be of high public interest. In this study, we aimed to compare incarcerated sexual offenders who reported with those that denied being HIV-positive, in terms of drug misuse, impulsiveness levels and recidivism risk. It was a cross-sectional research with 198 adult male offenders sentenced only for sexual crimes, recruited and interviewed in a Brazilian Penitentiary.

HIV-infected sexual offenders showed higher sexual impulsiveness, more problems with drug misuse and higher recidivism risk than their counterparts. The total sample achieved a power of $93 \%$ and $87 \%$ to detect distinctions between both groups as regards sexual impulsiveness and problems with drug misuse, respectively.

HIV-infected sexual offenders can be a distinguished group and new and effective management strategies should urgently be re-thought and put forward for them.
\end{abstract}

Keywords: Sexual offenders, HIV infection, Sexual violence, Prisoners.

\section{INTRODUCTION}

Although the prevalence of HIV infection in the Brazilian population at large has remained stable at around $0.6 \%$ since 2004, HIV prevalence rates among incarcerated offenders in Brazil has been estimated to be approaching $14 \%[1,2]$. Only a small percentage of the prevention and management programs have focused on this at-risk group and the majority of such programs are based on AIDS education and condom distribution, inclusively inside prisons [3].

Incarcerated sexual offenders constitute a population of great concern because many of them show a large percentage of psychiatric and psychological problems and dangerous sexual behaviors, which puts them at risk for contracting and transmitting HIV [4, 5]. However, the HIV prevalence among sexual offenders is unknown, which partially contributes to the unavailability of the data on the rates of HIV transmission during sexual offenses [6]. In addition, it is important to consider that the existent data on sexual violence prevalence are not totally reliable, because many statistics are underestimated [7].

Different psychiatric and psychological problems, such as those related to impulse control, drug misuse, personality and sexual preference disorders, are usually verified among sexual aggressors $[7,8]$. Despite this, only a few of these

*Address correspondence to this author at the Avenida Angélica, $\mathrm{n}^{\circ}$ 2100/13. Consolação. São Paulo - S.P. CEP: 01228-200, Brazil; Tel: (+5511) 3120-6896; Fax: (+5511) 3120-6896; E-mail: dbaltieri@uol.com.br inmates receive adequate treatment inside or outside prison to improve their quality of life as well as reducing their recidivism risk [9-11]. Evaluating these data and considering that the sexual aggression is a contributing factor for HIVtransmission direct and indirectly, it is surprising that to date few studies have examined HIV-infected sexual offenders or set up evidence-based prevention, treatment and management strategies for this population.

Evidence suggests that victims of sexual violence or abuse are not only at high risk of contracting HIV (direct effect), but also at increasing chance of having future psychological and interpersonal sequelae that prompt them to exhibit risky sexual behaviors (indirect effect) $[12,13]$. For instance, whilst rates of childhood sexual and physical abuse in the general population are estimated at about $20 \%$, the rates in HIV-positive women are around 40\% [14].

Studies have shown that personality aspects, mainly those related to a poor impulsive control, can predate the HIV infection or even facilitate dysfunctional coping among people who have already been infected $[15,16]$. Also, diverse researches have confirmed the close relationship between drug misuse and risky sexual behaviors [17-19]. In spite of the heterogeneity of sexual offenders, serious alcohol and drug problems as well as high impulsiveness have been commonly diagnosed in this population $[7,20]$. Herein, a great challenge would be investigate in which aspects or degrees infected and non-infected sexual offenders can be different as to impulsiveness and drug misuse.

In line with data pointing out that many people who contract HIV can be described as "vulnerable" and that such 
vulnerability can be derived from some disorders of psychiatric nature or as obvious as the result of financial, social or geographical problems $[13,21,22]$, this study aimed to evaluate impulsiveness levels and drug problems between infected and non-infected incarcerated sexual offenders.

\section{METHODS}

\section{Design}

This study was part of another research carried out inside a specific penitentiary for sexual crimes in the State of São Paulo, Brazil [23]. It was a cross-sectional study, where the subjects provided information in a face-to-face interview. Convicts sentenced only for sexual crimes were evaluated with questionnaires on sociodemographic characteristics, criminological aspects, alcohol and drug consumption history, sexual and general impulsiveness, and recidivism risk.

This study was carried out inside penitentiary with the inmates serving a sentence. The access to the Penitentiary was given by the Penitentiary Counseling of São Paulo State and the Penitentiary Administration Secretariat of São Paulo State.

\section{Participants}

From 2004 to 2006, all 218 sexual offenders (including children molesters, sexual offenders against adults and sexual aggressors against adolescents) serving a sentence only for serious sexual crimes in the Penitentiary of Sorocaba - São Paulo - Brazil were recruited. Of these 218 convicts, 8 refused to take part in this study, 10 were released on parole before our evaluation and 2 were excluded for being unable to sign a consent report. No selected subject was mentally retarded or severely mentally disordered (e.g. psychotic or mood disorders) that would deserve special treatment in forensic hospitals.

One hundred and ninety-eight males (mean age 39.4 years, range $20-70$ years), convicted of rape $(n=41)$ or child / adolescent molestation $(n=157)$, participated in this study. Their mean education was 6.0 (S.D. 2.9) years, and their mean sentence 136.5 (S.D. 106.5) months. They were serving a sentence in one of the three penitentiaries for sexual offenders in the State of São Paulo, Brazil (Penitentiary of Sorocaba). In fact, sexual offenders must be confined in special correctional facilities because they can be at risk in common prisons.

\section{Procedure}

Following the Law $n^{\circ} 11.106 / 2005$, sexual crimes were defined as Rape (the crime of having sexual intercourse with a woman or girl forcibly and without her consent, or with a girl below the age of consent, which is 14 years old according to Brazilian Laws, also called 'Statutory Rape') and Indecent Assault (libidinous acts committed by a man against men or women). As defined by this law, the presumption of violence is established when the victim is under fourteen.

All information about the number of victims involved was obtained from the official registers, which were available for the researchers. All participants signed an informed consent form to be interviewed. Inmates who refused to participate, as well as the blind convicts were excluded from the study. This study was approved by the Ethical Department of the Medical School of the University of São Paulo, Brazil.

\section{Measures}

Participants were evaluated with the CAGE Questionnaire [24], the Drug Abuse Screening Test (DAST) [25], the Short Alcohol Dependence Data (SADD) [26], the Sexual Addiction Screening Test (SAST) [27], the Barratt Impulsiveness Scale - version 11 (BIS-11) [28], and the Static-99 [29].

The CAGE questionnaire was originally developed to briefly screen for clinically significant alcohol problems in many different settings. The CAGE contains four yes-no items that can be administered in a self-report or clinicalinterview format. A score of 2 or higher is considered clinically reliable and should raise the clinician's index of suspicion that the individual has an alcohol-related problem. The DAST was delineated to provide a quantifiable selfreport instrument for use in clinical and non-clinical settings to detect drug abuse or dependence pertaining to a range of psychoactive drugs. The original version of the DAST contains 28 yes-no questions that can also be administered in a self-report or clinician-interview format. The overall score can range from 0 to 29 based upon the sum of individual items. A cutoff score of 6 or more indicates a probable drug use problem. The SADD was designed to be sensitive across the full range of alcohol dependence and to be relatively free of sociocultural influences. The SADD contains 15 items, each one with four possible answers: never, a few times, many times, always. A cutoff score of 20 or more suggests severe alcohol dependence. The SAST was developed to assist in the assessment of sexually compulsive or "addictive" behaviors. Designed in cooperation with hospitals, treatment programs, private therapists, and community groups, the SAST provides a profile of responses which help to discriminate between addictive and nonaddictive behavior. The SAST contains 25 yes-no questions that can also be provided in a self-report or clinicianinterview format. A cutoff score of 6 or more can indicate a problem of addiction to sex. The current version of Barratt Impulsiveness Scale, version 11, was developed to assess impulsivity. This scale looks at impulsivity in terms of three domains: motor, non-planning and attentional impulsiveness. This instrument was designed to aid in the description of impulsiveness in psychiatrically healthy individuals and to explore the role of impulsivity in psychopathology. This questionnaire can be self-administered and it has 30 items scored on a 4-point scale. There are no standardized norms for the BIS-11. The Static-99 is a brief actuarial instrument created to estimate the probability of sexual and violent recidivism among adult males who have already been convicted of at least one sexual offense against a child or non-consenting adult. This scale contains 10 items, and the minimum information required for scoring Static-99 is the pre-existing relationship between the victim and the offender. Although potentially useful, an interview with the offender is not required to score this scale. Even though the Static-99 has not been validated in Brazil, we decided to use it because its items are directly associated with factors 
implicated in the recidivism risk, according to some previous studies. Reliability and validity studies on all these questionnaires have already been done.

The participants also completed a standard questionnaire seeking data on sociodemographic variables, penal status, alcohol and drug-consumption history, number of victims, history of criminal activities and HIV-status. The legal reports and medical records were also reviewed.

Although the HIV-testing is not compulsory for inmates, they are offered the opportunity to know their HIV serostatus. As prisons in general allow conjugal visits, the HIV-testing has been strongly recommended to all of these inmates. For those offenders who reported being HIVinfected, the tests were verified by the researchers.

\section{RESULTS}

Seven inmates (3.5\%) reported being HIV-infected and 191 (96.5\%) were HIV-negative. There were no significant differences between both groups as regards mean age, monthly income prior to the imprisonment, race, educational level, time of penalty, number of victims offended, victim's age, history of criminal recidivism, and personal history of being sexually abused in childhood. However, six (85.7\%) HIV-infected sexual offenders reported being single as against $61(31.9 \%)$ HIV-negative sexual offenders $\left(\chi^{2}=8.82\right.$, $2 \mathrm{df}, \mathrm{p}=0.01)$.

A 2 X 5 MANOVA was conducted with the sexual offenders groups (according to the HIV serostatus) as the independent variable and the psychometric variables (BIS-11, SAST, DAST, SADD, STATIC-99) total scores entered as the dependent ones. This overall MANOVA was significant

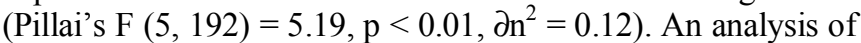
univariate effects did not show significant effects only for SADD. The remaining variables were reliably higher for the group of HIV-infected sexual offenders (Table 1).

Due to the small sample size, we did not perform any regression analysis to evaluate the influence of possible predictors (independent variables) on group membership (HIV-infected and non-infected sexual offenders). Thus, we used a more stringent statistical criterion of $p$ value $<0.01$ to infer reliable differences between the groups during univariate analyses.

\section{Power Analysis}

The PASS statistical program was used in a $t$-test for two independent samples with common variance to calculate the power of the present sample size. The total sample achieved a power of $93 \%$ and $87 \%$ to detect distinctions between HIV-infected and non-infected sexual offenders as regards the mean difference in the sexual impulsiveness levels and the severity of drug misuse, respectively. This computation assumes that the mean difference is 6.1 and 8.8 , and the common within-group standard deviation is 4.6 and 7.4, with respect to the impulsiveness levels and drug misuse, respectively. Also, this sample size enabled us to report the mean difference with a precision ( $95 \%$ confidence level) of plus / minus 3.4 and 5.6 points, respectively.

\section{DISCUSSION}

HIV-infected sexual offenders showed higher general and sexual impulsiveness, greater severity of drug misuse and higher recidivism risk than non-infected ones. This subgroup can represent an "extra-burden" to policy makers mainly in societies where prevention, therapeutic and political strategies focused on sexual offenders are still in their infancy [10].

Although it may be true that the treatment of sexual offenders can reduce their recidivism risk, we must consider that this population is extremely heterogeneous and different types of management can be necessary for different types of aggressors [30-32]. If HIV-infected sexual offenders consist of a unique group, treatment protocols should be better individualized to help them modify their sexual choices, improve social and interpersonal skills, and avoid more undesirable consequences for themselves and their possible victims. Thus, this information should be useful for the elaboration of multimodal interventions for this population.

In reality, HIV infection is a major health problem for prisons around the world. Besides increasing the risk of HIV transmission, the imprisonment status can difficult selfdisclosure of previous tests or even inhibit felons from taking a new exam (essentially, where HIV tests are not compulsory). In Brazil, there are 1,779 penal institutions that host about 473,626 inmates of whom about $40 \%$ are in the State of São Paulo. Prisoners are predominantly male (93\%) and accused of committing mainly burglary and larceny. Around $4 \%$ of inmates are serving a sentence for a serious sexual crime (rape and / or indecent assault). As our penitentiary system has no mandatory HIV-testing, HIV prevalence among inmates in general is absolutely elusive.

Due to sample size, this study does not provide enough reason for believing that HIV-infected sexual offenders are

Table 1. Psychometric tests: Means and Standard Deviations

\begin{tabular}{|c|c|c|c|c|}
\hline Variables & HIV-Positive Sexual Offenders $(\mathbf{n}=7)$ & HIV-Negative Sexual Offenders $(\mathbf{n}=\mathbf{1 9 1})$ & Test & $\mathbf{p}$ \\
\hline \hline SADD, mean (SD) & $21.14(13.35)$ & $12.86(14.17)$ & $t=1.52,196 \mathrm{df}$ & $0.13^{\mathrm{a}}$ \\
\hline DAST, mean (SD) & $12.43(12.15)$ & $3.63(7.17)$ & $\mathrm{U}=408.50$ & $0.03^{* \mathrm{~b}}$ \\
\hline BIS-11, mean (SD) & $85.14(10.24)$ & $71.16(10.96)$ & $t=3.32,196 \mathrm{df}$ & $<0.01^{* * \mathrm{a}}$ \\
\hline SAST, mean (SD) & $10.71(6.77)$ & $4.58(4.50)$ & $\mathrm{U}=274.50$ & $<0.01^{* * \mathrm{~b}}$ \\
\hline STATIC-99, mean (SD) & $4(1.29)$ & $2.11(1.81)$ & $t=3.34,196 \mathrm{df}$ & $0.01^{* * \mathrm{a}}$ \\
\hline
\end{tabular}

$* \mathrm{p}<0.05$.

$* * \mathrm{p}<0.01$.

${ }^{\mathrm{a}} \mathrm{t}$ Student test ${ }^{\mathrm{b}}$ Mann-Whitney test.

$\mathrm{SADD}=$ Short Alcohol Dependence Data; DAST $=$ Drug Abuse Screening Test; BIS-11 = Barratt Impulsiveness Scale; SAST = Sexual Addiction Screening Test. 
significantly different from non-infected sexual offenders. However, if we consider that a lot of sexual aggressors show diverse psychiatric disturbances, the co-occurrence of HIV infection may significantly affect pre-existing problems and create other ones.

Although a significant sum of efforts must be carried out to treat sexual offenders in general, and maybe paying more attention to HIV-infected ones, it is important to note that all sex offenders are more stigmatized than other types of prisoners and that the public outcry against them can harm the development of effective treatment programs [10]. In fact, sexual offenders ostracized by society experience a significant amount of stress, depression, and hopelessness, which can affect their ability to function as successful member of society. Also, stigmatization and ostracism contribute to amplify their deviance and hinder any protection or therapeutic measures inside and outside prisons [33].

For many prisoners, incarceration is the only time that they can access primary care. In some places, efforts have been done to link jail-based therapeutic programs to community-based ones in order to facilitate an adequate transition and to maintain the treatment previously initiated for HIV-infected offenders [34]. In comparison to some types of non-sexual offenders, the treatment of HIV-infected sexual offenders must involve a team of different professionals, aiming to decrease the recidivism risk, to improve their quality of life and to treat different types of diseases.

Sexual violence is a notable public health problem and the presence of sexually transmitted infections (STIs) in any inmate condemned for a sexual crime should call for more attention [35]. Considering that a great prevalence of incarcerated sexual offenders shows high sexual impulsiveness and preference sexual disorders [8, 23], the recidivism risk among these non-treated prisoners is a constant issue.

Diverse studies have described the limitations of HIV education-based prevention strategies on actual risk reduction [36]. Other aspects, such as impulsiveness and personality traits, should be taken into account during the development of prison and community-based management strategies. Specialized health programs for this population should include rigorous evaluation of characteristics and necessities of each sex offender. To those with higher risk behaviors, the staff must be prepared to establish a more empathic relationship. In the cases where certain traits of personality are found or even suspected, the staff must make efforts to promote the adherence to a specific program. A useful technique is to emphasize the fact that the sex offenders can have an "extra-endowment", an above-average amount of feelings, and this can favor their risky conducts. In fact, to promote the therapeutic adherence of patients with certain personality traits is not an easy task; despite this, to enable our patients to see how their behavior is disastrously powerful may create a desire to overcome the problem.

Despite these recommendations, we know that released inmates face barriers to accessing substance abuse, medical, and mental health treatment programs [37]. In particular, barriers to health care include the absence of discharge planning, insufficient health insurance, and discrimination against ex-inmates, especially when these ex-inmates are sexual aggressors. Besides, the public perception that sexual offenders cannot be rehabilitated may actually increase deviance and hinder any protective and therapeutic measures.

\section{REFERENCES}

[1] Ministério da Saúde. Brasil: Boletim Epidemiológico DST / AIDS. Ano V. N ${ }^{\circ} 1$. Junho a Dezembro de 2007 / Janeiro a Junho de 2008. http://www.aids.gov.br/data/documents (accessed April 05, 2011).

[2] Burattini, M.; Massad, E.; Rozman, M.; Azevedo, R.; Carvalho, H. Correlation between HIV and HCV in Brazilian prisoners: evidence for parenteral transmission inside prison. Rev. Saude Publica., 2000, 34, 431-6.

[3] UNAIDS: AIDS epidemic update. UNIAIDS: Geneva, 2009.

[4] Emusu, D.; Ivankova, N.; Jolly, P.; Kirby, R.; Foushee, H.; Wabwire-Mangen, F.; Katongole, D.; Ehiri, J. Experience of sexual violence among women in HIV discordant unions after voluntary HIV counselling and testing: a qualitative critical incident study in Uganda. AIDS Care, 2009, 21, 1363-70.

[5] Cameron, E. Compulsory HIV testing of sexual offenders. S. Afr. Med. J., 2002, 92, 252-3.

[6] Dosio, D.; Boer, D. P. Constructing hope: a multi-agency programme model for young sex offenders living with HIV/AIDS in South Africa. Sex Offender Treat., 2007, 2, 1-7.

[7] Baltieri, D. A.; de Andrade, A. G. Drug consumption among sexual offenders against females. Int. J. Offender Ther. Comp. Criminol., 2008, 52, 62-80.

[8] Dunsieth, N. W., Jr.; Nelson, E. B.; Brusman-Lovins, L. A.; Holcomb, J. L.; Beckman, D.; Welge, J. A.; Roby, D.; Taylor, P., Jr.; Soutullo, C. A.; McElroy, S. L. Psychiatric and legal features of 113 men convicted of sexual offenses. J. Clin. Psychiatry, 2004, 65, 293-300.

[9] Giotakos, O.; Bourtsoukli, P.; Paraskeyopoulou, T.; Spandoni, P.; Stasinos, S.; Boulougouri, D.; Spirakou, E. Prevalence and risk factors of HIV, hepatitis B and hepatitis $\mathrm{C}$ in a forensic population of rapists and child molesters. Epidemiol. Infect., 2003, 130, 497500 .

[10] Baltieri, D. A.; de Andrade, A. G. Treatment of paraphilic sexual offenders in Brazil - Issues and controversies. Int. J. Forensic Ment. Health., 2009, 8, 185-95.

[11] Baltieri, D. A. Drugs, Sex and Crime - Empirical Contributions. Bentham Science Publishers: New York, 2009.

[12] Clum, G. A.; Andrinopoulos, K.; Muessig, K.; Ellen, J. M. Child abuse in young, HIV-positive women: linkages to risk. Qual. Health Res., 2009, 19, 1755-68.

[13] Gwandure, C. Sexual assault in childhood: risk HIV and AIDS behaviours in adulthood. AIDS Care, 2007, 19, 1313-5.

[14] Kalichman, S. C.; Sikkema, K. J.; DiFonzo, K.; Luke, W.; Austin, $\mathrm{J}$. Emotional adjustment in survivors of sexual assault living with HIV-AIDS. J. Trauma Stress, 2002, 15, 289-96.

[15] Fassino, S.; Leombruni, P.; Amianto, F.; Abbate-Daga, G. Personality profile of HIV outpatients: preliminary results and remarks on clinical management. Psychother. Psychosom., 2004, 73, 361-5.

[16] Johnson, J. G.; Williams, J. B.; Goetz, R. R.; Rabkin, J. G.; Remien, R. H.; Lipsitz, J. D.; Gorman, J. M. Personality disorders predict onset of Axis I disorders and impaired functioning among homosexual men with and at risk of HIV infection. Arch. Gen. Psychiatry, 1996, 53, 350-7.

[17] Cavazos-Rehg, P. A.; Spitznagel, E. L.; Schootman, M.; Strickland, J. R.; Afful, S. E.; Cottler, L. B.; Bierut, L. J. Risky sexual behaviors and sexually transmitted diseases: a comparison study of cocaine-dependent individuals in treatment versus a communitymatched sample. AIDS Patient Care STDS, 2009, 23, 727-34.

[18] Weidel, J. J.; Provencio-Vasquez, E.; Grossman, J. Sex and drugs: high-risk behaviors at circuit parties. Am. J. Mens. Health, 2008, 2 , 344-52.

[19] Browne, D. C.; Clubb, P. A.; Wang, Y.; Wagner, F. Drug use and high-risk sexual behaviors among african american men who have sex with men and men who have sex with women. Am. J. Public Health, 2009, 99, 1062-6. 
[20] Peugh, J.; Belenko, S. Examining the substance use patterns and treatment needs of incarcerated sex offenders. Sex Abuse, 2001, 13, 179-95.

[21] Martins, S. S.; Tavares, H.; da Silva Lobo, D. S.; Galetti, A. M.; Gentil, V. Pathological gambling, gender, and risk-taking behaviors. Addict. Behav., 2004, 29, 1231-5.

[22] Wechsberg, W. M.; Lam, W. K.; Zule, W.; Hall, G.; Middlesteadt, R.; Edwards, J. Violence, homelessness, and HIV risk among crack-using African-American women. Subst. Use Misuse, 2003, 38, 669-700.

[23] Baltieri, D. A.; Andrade, A. G. Comparing serial and nonserial sexual offenders: alcohol and street drug consumption, impulsiveness and history of sexual abuse. Rev. Bras. Psiquiatr., 2008, 30, 25-31.

[24] Mayfield, D.; McLeod, G.; Hall, P. The CAGE questionnaire: validation of a new alcoholism screening instrument. Am. $J$. Psychiatry, 1974, 131, 1121-3.

[25] Skinner, H. A. The drug abuse screening test. Addict. Behav., 1982, 7, 363-71.

[26] Raistrick, D.; Dunbar, G.; Davidson, R. Development of a questionnaire to measure alcohol dependence. Br. J. Addict., 1983, 78, 89-95.

[27] Schneider, J. P. How to recognize the signs of sexual addiction: asking the right questions may uncover serious problems. Postgrad. Med., 1991, 90, 171-182.

[28] Patton, J. H.; Stanford, M. S.; Barratt, E. S. Factor structure of the Barratt impulsiveness scale. J. Clin. Psychol., 1995, 51, 768-74.
[29] Hanson, R. K.; Thornton, D. Improving risk assessments for sex offenders: a comparison of three actuarial scales. Law Hum. Behav., 2000, 24, 119-36.

[30] O'Reilly, G.; Carr, A.; Murphy, P.; Cotter, A. A controlled evaluation of a prison-based sexual offender intervention program. Sex Abuse, 2010, 22, 95-111.

[31] Hanson, R. K.; Gordon, A.; Harris, A. J.; Marques, J. K.; Murphy, W.; Quinsey, V. L.; Seto, M. C. First report of the collaborative outcome data project on the effectiveness of psychological treatment for sex offenders. Sex Abuse, 2002, 14, 169-94.

[32] Woodrow, A. C.; Bright, D. A. Effectiveness of a Sex Offender Treatment Programme: A Risk Band Analysis. Int. J. Offender Ther. Comp. Criminol., 2011, 55, 43-55.

[33] Schiavone, S. K.; Jeglic, E. L. Public perception of sex offender social policies and the impact on sex offenders. Int. J. Offender Ther. Comp. Criminol., 2009, 53, 679-95.

[34] Rich, J. D.; Holmes, L.; Salas, C.; Macalino, G.; Davis, D.; Ryczek, J.; Flanigan, T. Successful linkage of medical care and community services for HIV-positive offenders being released from prison. J. Urban Health, 2001, 78, 279-89.

[35] Bechtel, K. Sexual abuse and sexually transmitted infections in children and adolescents. Curr. Opin. Pediatr., 2010, 22, 94-9.

[36] Alemagno, S. A.; Stephens, R. C.; Stephens, P.; Shaffer-King, P.; White, P. Brief motivational intervention to reduce HIV risk and to increase HIV testing among offenders under community supervision. J. Correct. Health Care, 2009, 15, 210-21.

[37] Hudson, A. L.; Nyamathi, A.; Bhattacharya, D.; Marlow, E.; Shoptaw, S.; Marfisee, M.; Leake, B. Impact of prison status on HIV-related risk behaviors. AIDS Behav., 2010, 15, 340-6.

(C) Baltieri and Boer; Licensee Bentham Open.

This is an open access article licensed under the terms of the Creative Commons Attribution Non-Commercial License (http://creativecommons.org/licenses/by$\mathrm{nc} / 3.0 /$ ) which permits unrestricted, non-commercial use, distribution and reproduction in any medium, provided the work is properly cited. 